\title{
Guidelines for the Administration of Oral Examinations: Review and Opinion
}

\author{
MOHAMmED M.S. JAN, MB.Ch.B.,FRCP(C)* and AMIRA R. Al BuHAIRI, MB.Ch.B.,FRCP(C)** \\ * Department of Pediatrics (Neurology), Faculty of Medicine \& Allied Sciences, \\ King Abdulaziz University and \\ ** Department of Internal Medicine **, King Khalid National Guard Hospital, \\ Jeddah, Saudi Arabia
}

\begin{abstract}
Practical oral examinations are important and are frequently a difficult part of medical school and board examinations. They represent an accurate and direct mean of assessing the student's interaction with patients and their clinical and technical skills. This paper reviews an outline for the administration of oral examinations. The review is based on the medical literature, detailed discussions with many senior examiners from different medical systems, and the author's personal experience. In summary, although the examiner's judgment is crucial, some general rules remain important for fair and consistent evaluation of students. Firstly, the examiner's attitude should be as friendly as possible and his or her objectives are to assess the student's medical competence and practical safety and does not help them pass or fails them. Secondly, scoring should be based on a model answer or well-accepted medical practices for a consistent rating. Finally, each examiner should give an independent score before discussing the final rating with the other examiners.
\end{abstract}

Keywords: Oral Examination, Guidelines, Evaluation, Review, Student.

\section{Introduction}

Practical oral examinations are important and frequently a difficult part of medical school and board examinations ${ }^{[1,2]}$. They represent an accurate and direct means of assessing the student's interaction with patients and their clinical and technical skills ${ }^{[3-6]}$.

Correspondence \& reprint requests to: Dr. Mohammed S. Jan, Department of Pediatrics (Neurology), P.O. Box 80215, Jeddah 21589, Saudi Arabia.

Accepted for Publication: 14 December 2001 Received: 31 July 1999. 
Limited references are available for examiners regarding the proper administration of oral examinations $^{[2]}$. Although each institute may have some general outlines for their examiners, specific guidelines are not well documented in the medical education literature. The styles and personalities of different examiners may vary, however, consistency in the conduct of examiners and their evaluation is critical.

This paper reviews an outline for the administration of oral examinations. The review is based on the medical literature, detailed discussions with many senior examiners from different medical systems, and the author's personal experience. Although the examiner's judgment is crucial, some general rules remain important for fair and consistent evaluation of students ${ }^{[2]}$.

\section{General Rules:}

1) The examiner's attitude should be as friendly as possible.

2) The objectives are to assess the student's medical competence and practical safety.

3) Scoring should be based on a model answer or well-accepted medical practices.

4) Each examiner should give an independent score before discussing the final rating.

Introduction of Oral Examination: Most students are anxious during oral examinations. This anxiety, particularly in males, is associated with a lower oral score ${ }^{[7]}$. Therefore, the examiner's initial contact with the student should be as friendly as possible. Examiners should try to show respect by standing, smiling, and shaking the student's hand. The examiner needs to introduce him or herself and the other examiners by name. This approach may make the student feel more comfortable and therefore less anxious. The same approach should be applied with every student even at the end of the day when the examiner becomes tired. Examiners tend to be more sensitive and friendly to students who show excessive nervousness. This may be unfair as some anxious students may show less anxiety reactions than others ${ }^{[2]}$. Examiners should try their best to be consistent in reacting to the anxiety reactions of different students.

Initial Discussion: In the beginning of the discussion, the examiner needs to allow the student to speak uninterrupted. This could ease their excessive anxiety and improve their performance as most will feel better after the initial few minutes of the discussion. Starting with easier and general questions and then proceeding to more difficult and specific ones could lead to smoother performance and therefore more accurate overall evaluation. Asking one question at a time is better than asking several questions at once.

Tips during the discussion: Maintenance of eye contact is required for proper interaction with students. If eye contact is avoided, a wrong message may be conveyed that the examiner is feeling bored or the student is completely off track. Examiners should always give the student some time to think in response to the asked questions and then maintain the direction of the discussion without allowing the student to gain control or change the topic. It is best if the examiner avoids giving a response to the student's answers either verbally, by facial expressions, or by other body language. The student 
may become confused or his or her performance may deteriorate if signs of dissatisfaction is conveyed. Also, arguing or correcting the answers of the student should be avoided. Sometimes, an anxious student may misunderstand the question before concluding that the student did not know the answer. It is clear that he or she does not know the answer, switching to another question would avoid time wasting. Indirect or vague questions should be avoided. Trap questions like giving a hint toward a wrong answer to mislead the student are inappropriate. Examiners should always remember that their objectives are not to fail the students, but rather to assess their clinical competence and practical safety. Many think that this teaching will never be forgotten and is in the student's best interest. Clearly this will make the student believe that he or she is lacking the important knowledge and therefore best avoided. Jokes should also be avoided because of possible misinterpretation by an anxious student. It is difficult to use humour with every student and therefore unfair when used inconsistently ${ }^{[2]}$.

End of the discussion: At the end of the discussion it is common to hurry or become less friendly. This is more common at the end of the day when several students have been examined and the examiners are getting tired. Examiners should try their best to remain patient and friendly. At the end of the examination, smile, shake the student's hand, and wish him or her good luck. Many students try to get an evaluation from the examiner. Giving an overall impression by saying "you did well, you are fine, or you do not need to worry, is best avoided. The lack of this feedback to other less obviously worried candidates would be unfair.

Rating: The rating should be based on a model answer or well-accepted medical practices for a consistent rating. The objective is to assess the student's clinical competence, defined as the professional skills required to act and represent the fundamental background required for the performance ${ }^{[8]}$. Students with better communicative skills may get better rating than deserved ${ }^{[2,9]}$. Regardless of the content of a student's responses on an oral examination, evaluators were strongly influenced by how well the student communicates ${ }^{[10]}$. Other possible biases that may influence the overall rating include: gender, age, size, looks, ethnic origin, and dress. Examiners should be aware of these personal differences and adhere to a consistent rating guidelines. Another bias is the so called "last student effect", which is the tendency to rate a student in relation to the last examined one. Other factors that should have little influence on the student's overall score include: style, personality, aggressiveness, and general attitude. There is a general tendency to give a borderline pass score rather than a clear fail score as it would be safer and would give the student the "benefit of the doubt". It is important to remember that the objectives are not to help the students pass. Examiners should preferably assign a clear pass or fail score as it would be in the best interest of students, patients, and the community. Each examiner should give an independent score before discussing the final rating with the other examiners. This would prevent the possible positive or negative influences on the final rating. The final rating should be discussed thoroughly by all examiners particularly when there are discrepancies in marking. Ideally, the final mark should equal the mean of marks given by all examiners because of the poor inter-rater reliability of marking by different oral examiners ${ }^{[7,11]}$. 
In conclusion, this paper reviewed in detail an outline for the administration of practical oral examinations. Various techniques of questioning and possible pitfalls were discussed. The examiner's attitude should be as friendly as possible and their objectives are to assess the student's medical competence and practical safety. The scoring should be based on a model answer or well-accepted medical practices for consistent ratings. Finally, each examiner should give an independent score before discussing the final rating with the other examiners. Many examiners may already follow some of these proposed guidelines, however, the detailed outline should hopefully assist in educating new examiners about the administration of oral examinations.

\section{Acknowledgment}

To all the experienced examiners we worked with at King Abdulaziz University Hospital (Jeddah, Saudi Arabia), IWK-Grace Health Center, and the QEII Health Sciences Center, Dalhousie University (Halifax, Nova Scotia, Canada).

\section{References}

[1] Hardy KJ, Demos LL, McNeil JJ. Undergraduate surgical examinations: an appraisal of the clinical orals. Med Educ 1998; 32(6): 582-589.

[2] Ferron D. Guidelines for conduct of oral examinations. Annals RCPSC 1998; 3(1):28-30.

[3] Hammar ML, Forsberg PM, Loftas PI. An innovative examination ending the medical curriculum. Med Educ 1995; 29(6): 452-457.

[4] Baerheim A, Malterud K. Clinical examination in general practice - a consultation. Experiences after the first examination. Tidsskr Nor Laegeforen 1995; 115(11): 1368-1370.

[5] Hassett J, Luchette F, Doerr R, Bernstein G, Ricotta J, Petrelli N, Stulc J, Curl GR, Booth FM, Hoover E. Utility of an oral examination in a surgical clerkship. Am J Surg 1992; 164(4): 372-376.

[6] Herbert WN, McGaghie WCC, Droegemueller W, Riddle MH, Maxwell KL. Student evaluation in obstetrics and gynecology: self versus departmental assessment. Obstet Gynecol 1990; $76(3 \mathbf{~ P t}$ 1): $458-461$.

[7] Thomas CS, Mellsop G, Callender K, Cranshw J, Ellis PM, Hall A, MacDonald J, Silfverskiold $\mathbf{P}$, and Romas-Clarkson S. The oral examination: a study of academic and non-academic factors Med Educ 1993; 27(5): 433-439. Erratum in: Med Educ 1994; 28(1): 96.

[8] Sensi S, Guagnano MT. Assessment of clinical competence. The state of the art. Recenti Prog Med 1996; 87(9): 445-451.

[9] Lang NP, Rowland-Morin PA, Coe NP. Identification of communication apprehension in medical students starting a surgery rotation. Am J Surg 1998; 176(1): 41-45.

[10] Rowland-Morin PA, Burchard KW, Garb JL, Coe NP. Influence of effective communication by surgery students on their oral examination scores. Acad Med 1991; 66(3): 169-171.

[11] Schwiebert P, Davis A. Increasing inter-rater agreement on a family medicine clerkship oral examination - a pilot study. Fam Med 1993; 25(3): 182-185. 


\section{مراجعة ورأي عن طرق القيام بالامتحانات الشفوية}

***محد محمد سعيد جان* و أميرة راشد حمود البحيري

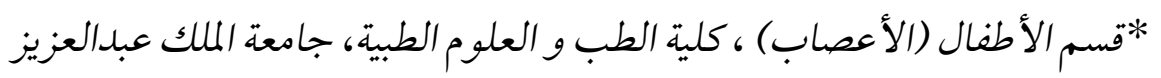

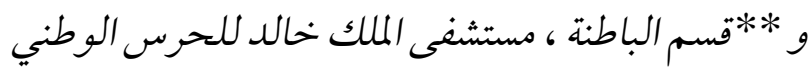

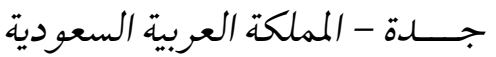

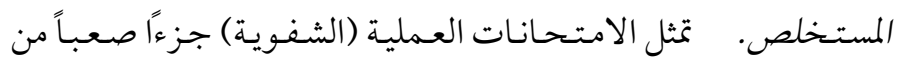

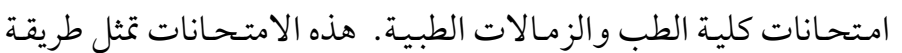

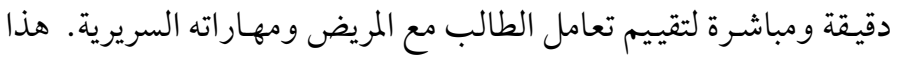

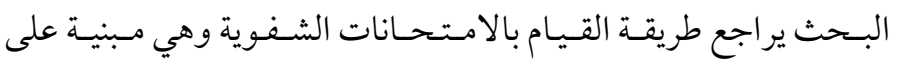

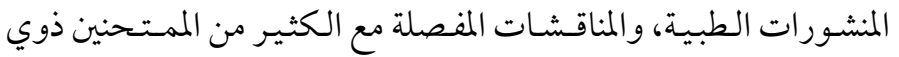

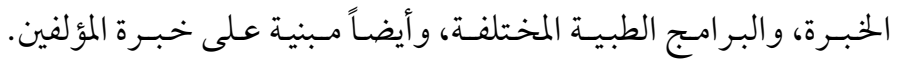

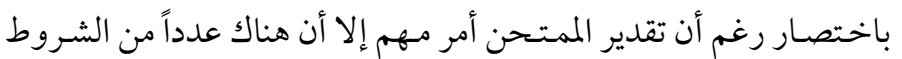

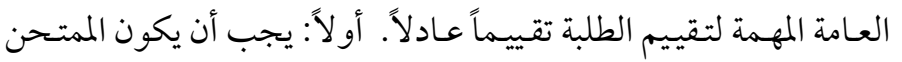

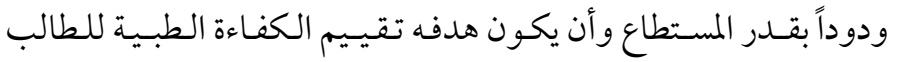

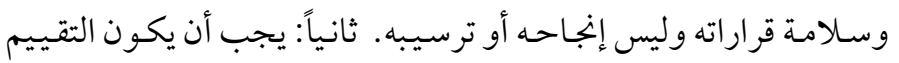
مبنياً على أجوبة مثالية أو ممارسات طبية متفق عليها للتقييم العادل. أخيراً

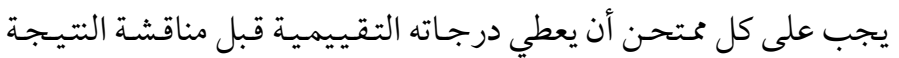

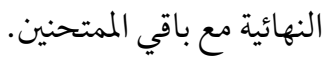

